\title{
Entre o português como língua estrangeira e as práticas interculturais comunicativas: estudo de caso em universidade colombiana
}

\author{
Cristine Gorski Severo \\ Universidade Federal de Santa Catarina \\ crisgorski@gmail.com \\ Daniela Viola \\ Universidade EAN \\ danielaviola@gmail.com
}

\begin{abstract}
Resumo
$\mathrm{O}$ artigo enfoca teórico-metodologicamente uma experiência de ensino de português como língua estrangeira em universidade colombiana voltada para a formação empresarial. Trata-se de propor uma abordagem de ensino bilíngue que considere a língua como prática social e não como objeto. Nesse caso, o enfoque da experiência bilíngue considera a língua portuguesa como mediadora de encontros interculturais. A partir disso, conceitos como translinguagem e prática social foram considerados em articulação teóricometodológica com a concepção de língua como gêneros discursivos. Buscouse uma visão contextualizada e sensível às práticas comunicativas e interculturais. Os resultados do projeto demonstram que o processo de aprendizagem de uma língua estrangeira não exige, necessariamente, que a língua tenha que ser sistematizada e autonomizada para ser ensinada. As práticas comunicativas bilíngues produzem hibridizações e amálgamas linguísticos que não devem ser vistos como "problemas", mas como recursos que possibilitam o processo de produção, negociação e compreensão de sentidos.
\end{abstract}

Palavras-chave: bilinguismo; PLE; hispanofalantes; prática comunicativa.

\section{Abstract}

The article presents a theoretical and methodological approach to the teaching of Portuguese as foreign language in a Colombian university focused on business training. We propose a bilingual teaching approach that considers language as social practices rather than theoretical objects. In this case, the 
focus of the project on the bilingual experience considers Portuguese language as a mediator of intercultural encounters. Concepts such as translinguagem and social practice were considered in theoretical and methodological integration with a concept of discursive genres. The results demonstrate that the process of learning a foreign language does not necessarily require that languages be systematized to be taught. Also, the bilingual communicative practices produced linguistic hybridizations and amalgams that should not be seen as "problems", but as resources that enable the meaning making process.

Palavras-chave: bilingualism; PFL; Spanish speakers; communicative practice.

\section{Introdução}

Este artigo pretende apresentar e discutir os resultados finais de um projeto de Português como Língua Estrangeira (PLE) aplicado na Escuela de Administración de Negocios (EAN), sediada em Bogotá, Colômbia. O projeto intitulado "Enseñanza del portugués a partir de géneros discursivos propios del entorno empresarial" foi desenvolvido no decorrer do ano de 2015 e se baseou na construção de experiências educacionais que fomentassem elementos de uma cultura acadêmica bilíngue Espanhol-Português. Em termos teórico-metodológicos, buscamos analisar o ensino de língua portuguesa para alunos colombianos a partir da construção de uma proposta de experimentação bilíngue, enfocando a Língua Portuguesa (LP) como mediadora de diálogos e experiências que se configuram como interculturais e bilíngues. Nosso foco não é considerar o PLE como objeto de ensino, mas como um eixo articulador de experiências interculturais que envolvem a relação dos alunos hispanofalantes com a língua portuguesa no contexto acadêmico, a despeito dos "níveis de proficiência" desses alunos em relação à LP. Maiores detalhamentos sobre o projeto são apresentados na terceira seção deste artigo.

Buscou-se, com isso, considerar as teorias e metodologias voltadas para a criação de contextos educacionais bilíngues a partir da língua tomada como prática social (Garcia, 2009; Garcia e Li, 2014). Para Garcia (2009), o ensino bilíngue deve ser visto a partir de uma perspectiva plural, sendo a única forma de se educar no século XXI, em diálogo com os encontros e desafios interculturais. A partir de uma perspectiva intercultural, nos apoiamos em uma concepção de língua 
tomada como prática social, em que o processo de aprendizagem da língua deve levar em conta os usos sociais linguísticos localmente contextualizados (Makoni e Pennycook, 2005; Moita Lopes, 2006; Canagarajah, 2004; Pennycook, 2010; Davies e Elder, 2010). Em diálogo com essa visão de língua como prática social, nos vinculamos, também, a uma abordagem teórico-metodológica centrada nos gêneros discursivos, entendidos como formas relativamente estáveis de interação sócio-verbal constituídas historicamente (Bakhtin, 19521953; Bakhtin, 1959-61; Nascimento e Rojo, 2014; Acosta-Pereira e Rodrigues, 2009; Kleiman, 1995; Kleiman, 1999). Os gêneros discursivos podem ser vistos como práticas comunicativas histórica e socialmente contextualizadas que se vinculam a esferas sócioideológicas diversas. No caso desse artigo, trata-se de analisar o papel dos gêneros discursivos na construção de uma experiência pedagógica bilíngue.

Tendo feita essa apresentação, o artigo se estrutura da seguinte maneira: inicialmente, apresentamos as concepções de língua e de ensino que norteiam as nossas reflexões, pontuando para um deslocamento da ideia de PLE como objeto de ensino em direção ao papel da LP como mediadora de experiências bilíngues (e translinguísticas); em seguida, discorremos sobre o projeto realizado na EAN, propondo pequenas análises a partir do referencial teórico apresentado. Por fim, seguem as conclusões.

\section{A construção de experiências bilíngues português-espanhol e a desconstrução da ideia de PLE como objeto}

Reconhecemos que, com o intenso processo de internacionalização da língua portuguesa (Severo, 2015; Diniz, 2015; Zoppi Fontana, 2009), uma série de pesquisas envolvendo o PLE, especialmente no Brasil, têm sido feitas, em busca da elaboração de materiais didáticos e metodológicos que possibilitem a construção de instrumentos pedagógicos que visem contemplar as especificidades linguísticas e a dimensão intercultural presente no PLE. Além disso, não é difícil presenciarmos notícias publicadas em mídias digitais e impressas sobre o crescimento do valor econômico da Língua Portuguesa, motivado pela ascensão do Brasil. A demanda por estudos 
sobre Língua Portuguesa como Língua Estrangeira (PLE), como Língua Adicional (LA), Língua de Herança (LH) ou Língua de Acolhimento tem produzido uma razoável mobilização de pesquisadores brasileiros e universidades brasileiras. Exemplos disso são a criação de cursos de graduação em PLE ou segunda língua na UNB, UFBA, Cefet-MG e UNICAMP, além de programas de pósgraduação que têm se voltado para reflexões teóricas e metodológicas sobre o assunto. Vale, ainda, mencionar o papel da SIPLE (Sociedade Internacional do Português como Língua Estrangeira) na difusão do tema, e as iniciativas do Ministério das Relações Exteriores, em parceria com a Capes, em promover a língua e cultura brasileiras através de Programas de Leitorado e de editais de Mobilidade Internacional para ensino de Língua Portuguesa (CAPES/AULP).

Exemplos governamentais em torno do PLE incluem os esforços do Instituto Internacional de Língua Portuguesa (IILP) na construção do portal do professor (http://www.ppple.org/o-portal), e da Rede Brasil Cultural ${ }^{1}$, que é gerenciada pela Divisão de Promoção da Língua Portuguesa (DPLP) do Ministério das Relações Exteriores. A Rede integra 24 Centros Culturais (sete localizados na América), cinco Núcleos de Estudo e 40 Leitorados, distribuídos em 45 países. Todos esses programas estão voltados para o ensino e difusão do português brasileiro. A Rede Brasil Cultural edita e publica o periódico Rede em Revista, que consta com duas edições já publicadas (http://redebrasilcultural.itamaraty.gov.br/publicacoes/revista). segunda edição, por exemplo, apresenta experiências de produção de material didático por professores de PLE na Tailândia e na Bolívia. O IILP e a Rede Brasil ilustram iniciativas governamentais que visam fortalecer a presença brasileira no contexto internacional, no embalo de políticas externas do Estado. Nesse caso, trata-se de casos em que a articulação entre língua, cultura e identidade é fortalecida, em prol de representações nacionalistas.

No contexto acadêmico e não-governamental, amplos debates têm sido encabeçados pela Sociedade Internacional de PortuguêsLíngua Estrangeira (http://www.siple.org.br/), que edita desde 2010 a

\footnotetext{
${ }^{1}$ Informações disponíveis em http://dc.itamaraty.gov.br/divisao-de-promocaoda-lingua-portuguesa-dplp-1. Acesso em 01 de fev. de 2016.
} 
Revista SIPLE, contando com oito edições digitais. A título de exemplo, os temas discutidos pelos trabalhos publicados pela revista incluem: aspectos culturais e linguísticos do PLE, as atitudes e crenças de alunos e professores envolvendo o PLE para diferentes públicos, PLE em diferentes contextos internacionais e nacionais, o ensino de português como língua de herança ou língua adicional, o potencial econômico da LP, PLE para fins específicos, ensino de português brasileiro como língua estrangeira, abordagens metodológicas, compartilhamento de experiências de ensino, provas de proficiência (Celpe-Bras), entre outros.

Dentre os poucos trabalhos que tematizam o PLE para hispanofalantes publicados nas oito edições da Revista SIPLE, mencionamos Rojas (2010), para quem um dos motivos que levam hispanofalantes a se cristalizarem no uso do "portunhol", ao invés de buscarem proficiência em LP, seria uma certa tolerância dos brasileiros em relação a essa "interlíngua". Contudo, consideramos os conceitos de fossilização e de interlíngua cunhados por Rojas delicados, pois reforçam as representações de línguas como códigos fixos e autônomos (Pennycook, 2010). Já Masello (2010) relaciona a falta de iniciativas de ensino de PLE em universidades latino-americanas à produção incipiente de conhecimentos teóricos e metodológicos, bem como de cursos formadores, que validem o PLE como um novo objeto de ensino. Corrêa (2011), por seu turno, defende uma política linguística que promova e legitime o português brasileiro como referência linguística junto ao Mercosul. Neto (et al., 2013), por sua vez, apresenta um breve panorama histórico do ensino de português e espanhol no Brasil, Argentina e Chile, sinalizando para o crescimento de oferta de PLE e ELE (Espanhol como LE) após políticas linguísticas e educacionais instauradas pelo Mercosul.

Dentre tais pesquisas, contudo, não identificamos nenhuma que opere com a articulação teórica que defendemos nesse artigo. Aqueles trabalhos tendem a reforçar ideias nacionalistas ou visões de língua como sistemas autônomos e abstratos, desconsiderando a complexidade das práticas comunicativas nos tempos contemporâneos e fluidos. Desse modo, consideramos que o diferencial teórico deste trabalho está em aproximar a abordagem de translinguagem (Garcia; Wei, 2014) de uma perspectiva de gêneros discursos (Bakhtin 1952- 
1953), em torno de uma concepção de língua como prática comunicativa contextualizada.

Assim, diferentemente das abordagens tematizadas por tais pesquisas, buscamos uma perspectiva dialógica, intercultural e bilíngue de PLE, em que o bilinguismo não seja visto como uma categoria que articularia duas línguas tomadas como individuais e separadas. Tratase de considerar o bilinguismo a partir de ideia de "práticas sociais bilíngues", que compreende redes comunicativas multilíngues complexas (Garcia, 2009), internamente dialogizadas (Bakhtin,1988), multimodais e multissemióticas (Pennycook, 2014; Blommaert, 2010). Diante disso, as práticas bilíngues não se restringem à objetificação curricular e didática da língua, transformando-a em um objeto a ser ensinado, conforme certas visões que constroem o PLE como um objeto autônomo e separado. Defendemos que a dimensão de "estrangeiridade" atribuída à LP deve favorecer uma perspectiva mais porosa e hibridizável de língua, ao invés de fortalecer concepções cristalizadas de língua e ideias nacionalistas.

Acreditamos que é preciso que as aulas explorem e tematizem a complexidade das práticas comunicativas bilíngues, colocando em tela o conceito de comunicação intercultural e de diálogo. Com isso, ideias como proficiência, falante nativo, competência linguística, língua materna e estrangeira passam a ser relativizadas, pois reproduzem concepções homogêneas e cristalizadas de língua que podem reforçar, por exemplo, tanto ideais nacionalistas (português brasileiro vs. português europeu) como a indústria das línguas (mercado dos materiais instrucionais). Diante disso, o bilinguismo deixa de ser visto em relação ao domínio proficiente de duas línguas separadas ensinadas isoladamente, para incorporar um leque de experiências bilíngues que ocorrem no continuum entre LP e LE.

Além disso, compreendemos que a educação bilíngue não deve ser vista como o ensino para alunos que já dominam duas línguas, ou que dominam uma língua e buscam aprender a segunda de forma adicional ou estrangeira. Alinhamo-nos à concepção que considera que o ensino deve ocorrer em ambas as línguas (espanhol e português) tomadas como produtos das práticas comunicativas - e não como objetos de ensino -, em busca da construção de uma formação intercultural e linguística mais ampla e interconectada. É dessa maneira que o ensino bilíngue se diferencia do ensino de língua adicional ou de 
língua estrangeira (Garcia, 2009). Nesse contexto, tornam-se comuns as práticas de tradução e de mistura de línguas (perguntar em uma língua e responder em outra, por exemplo) e de modalidades (escrita e oral), pois o enfoque passa a ser o conteúdo e a construção da compreensão mútua (Garcia, 2009).

Consideramos, portanto, que a língua está a serviço de processos contextualizados de ensino e aprendizagem, e não o contrário, integrando língua e conteúdo, em detrimento de um enfoque centrado na língua como objeto (Garcia, 2009; Freire,1996). Trata-se, com isso, de fomentar uma cultura bilíngue que desestabilize ideologias linguísticas monoglóssicas (Lopes, 2006; Canagarajah, 2004), em direção a uma perspectiva heteroglóssica e plurilíngue (Bakhtin, 1988). Além disso, atentamos para o fato de que as práticas comunicativas não ocorrem apenas centradas nas línguas, mas integram recursos multimodais e multissemióticos (Pennycook, 2014), que devem ser pedagogicamente explorados em sala de aula em busca da construção de compreensões mútuas e de negociações de sentido. Nesse contexto, a expressão linguajamento (languaging) sinaliza para o processo contínuo e inacabado de torna-se sujeito através de práticas linguísticas (Garcia; Wei, 2014).

No presente artigo, defendemos uma articulação teóricometodológica entre as concepções de língua como práticas comunicativas e a concepção de gêneros discursivos tomados como formas específicas de comunicação verbal. Ambas as concepções contextualizam os usos linguísticos, vinculando-os a esferas sócioideológicas da atividade humana. Os gêneros discursivos são enunciados relativamente estáveis, atrelados a esferas sociais específicas; tais enunciados carregam finalidades discursivas e se caracterizam por três elementos - estilo (recursos linguísticos selecionados), estrutura composicional e tema (Bakhtin, 1952-1953). Ao consideramos as experiências bilíngues que se realizam através da comunicação intermediada por gêneros discursivos, atentamos para o fato de que a língua não deve ser vista como estrutura, mas como enunciado caracterizado por ter um propósito discursivo, conteúdo, estilo e estrutura composicional. Assim, fenômenos como hibridismos linguísticos não serão vistos como "problemas", mas como elementos integrantes de um dado projeto discursivo coletivo e plural. 
Diante de uma perspectiva focada em práticas translinguísticas (Garcia; Wei, 2014), considera-se que a mistura de línguas - como a ideia de portunhol - deve ser vista à luz dos esforços empreendidos pelos falantes de produzirem sentidos a partir de práticas linguísticas complexas, o que descontrói a visão pejorativa do falante de portunhol como aquele que é deficiente em relação a alguma das duas línguas, como se essas línguas fossem unidades discretas e autônomas. Assim, as práticas pedagógicas centradas nessa abordagem teórica devem estar sensíveis para os esforços linguísticos dos sujeitos na construção de comunicação e na produção e compreensão de sentidos envolvendo as línguas.

Diante do exposto, corroboramos com a perspectiva de Garcia e Wei (2014) de que o translinguajamento (translanguaging) entendido como o envolvimento dos sujeitos com práticas discursivas bilíngues ou multilíngues - é uma abordagem que desloca a concepção de língua como objeto autônomo para uma concepção mais alargada, de práticas que dizem respeito àquilo que os sujeitos fazem com as línguas no processo de comunicação. Exemplos da translinguagem seriam o uso de diferentes línguas no contexto educacional, como escrever em espanhol e ler em português, ouvir em português e falar em espanhol, ou, então, misturar as modalidades (falada e escrita) na comunicação e hibridizar usos linguísticos (mistura de espanhol com português). Assim, o foco dessa perspectiva é a comunicação e não uma representação abstrata ou descontextualizada de língua. Nesse contexto, as práticas linguísticas são vistas como "um repertório linguístico com características que foram socialmente construídas como pertencentes a duas línguas separadas"2 (Garcia; Wei, 2014, p. 2).

Tendo feita essa contextualização e apresentação teórica sobre o conceito de língua e de ensino, a seguir apresentamos alguns casos de ensino de PLE para hispano falantes, em uma Universidade privada da Colômbia, que ilustram a perspectiva adotada aqui.

\footnotetext{
2 "one linguistic repertoire with features that have been socially constructed as belonging to two separate languages". As traduções são de nossa responsabilidade.
} 


\section{Práticas de bilinguismo envolvendo o português como língua estrangeira: experiência de projeto em universidade colombiana}

O projeto que motivou o presente artigo teve como objetivo geral construir uma experiência de ensino bilíngue Espanhol-Português em um contexto universitário colombiano (Bogotá) com enfoque empresarial. Para tanto, assumimos as seguintes etapas metodológicas na pesquisa:

(i) realizar um diagnóstico da realidade local, considerando o perfil dos professores que colaboraram com a pesquisa e as disciplinas cursadas pelos alunos;

(ii) construir um projeto-piloto de intervenção em sala de aula com vistas à criação de uma experiência bilíngue EspanholPortuguês.

(iii) avaliar a capacidade dos alunos de apreensão da língua através dos gêneros discursivos empresariais e não empresariais.

(iv) considerar as especificidades culturais e a importância do diálogo intercultural (Cavalcanti; Bortoni-Ricardo, 2007) no trabalho com uma perspectiva empresarial.

O objetivo desta seção não será apresentar detalhadamente as etapas metodológicas apresentadas acima, mas explorar o potencial teórico das discussões feitas no artigo, levando em conta algumas práticas linguísticas de sala de aula e tendo em vista a perspectiva de língua apresentada na seção anterior. Buscamos, no decorrer da pesquisa, problematizar a repartição da língua em habilidades ou competências distribuídas em fala, escrita, leitura e compreensão oral, em consonância com uma perspectiva de língua como prática social (Garcia, 2009; Pennycook, 2014). Ao considerarmos as línguas como práticas sociais em contextos bilíngues e interculturais, atentamos para a maneira como as línguas se hibridizam - em termos de língua, modalidades, gêneros - em prol do projeto discursivo dos alunos (Garcia; Wei, 2014).

Para uma breve contextualização, primeiramente, identificamos os perfis dos professores para a pesquisa e definimos sua formação para atuarem com uma abordagem teórica centrada na língua 
como prática social. Para tanto, tivemos alguns encontros presenciais com os docentes e orientadores pedagógicos com fins de conhecer suas propostas, objetivos e métodos de ensino. Tais encontros ocorreram no decorrer da Semana de las Lenguas, entre 31 de outubro de 2014 e 07 de novembro de 2014, na sede da EAN/Bogotá. Ressalta-se que este evento teve como proposta apresentar as diversas atividades linguístico-discursivas realizadas pelos alunos e docentes desta instituição, perpassada por uma série de palestras feitas por docentes estrangeiros vinculados às várias culturas cujas línguas são ensinadas nesta instituição (alemão, francês, italiano e português). Nosso enfoque, no decorrer da Semana das Línguas foi o ensino de português para hispano-falantes. Identificamos, no decorrer da Semana, uma proposta metodológica que motivasse diálogos interculturais: cada dia da semana era dedicado a uma das quatro línguas, sendo que as temáticas abordadas incluíam temas transversais, como economia, cultura e mundo empresarial. Nesse período, a partir da observação das atividades da Semana das Línguas e de conversa com os docentes e orientadores pedagógicos, redigimos nosso projeto-piloto de intervenção em sala de aula, que foi submetido à apreciação da coordenação dos cursos de línguas da Universidade EAN. O projeto foi institucionalmente vinculado ao grupo de investigação Linguística $e$ Comunicação Organizacional e à linha de pesquisa intitulada Bilinguismo e Segunda Língua.

Os docentes que participaram desta pesquisa constituíram um quadro heterogêneo: eram formados em Letras Português-Espanhol, Linguística Aplicada, Relações Internacionais e Negociação Intercultural. Consideramos que essa formação ampla contribuiu para um diálogo interdisciplinar em torno não apenas de questões linguísticas, mas, sobretudo, da construção de uma reflexão sobre as especificidades dos cursos da EAN voltados para a área de Negócios. Foram elencados, portanto, gêneros discursivos que dialogassem com as práticas profissionais e acadêmicas desses estudantes, sem desconsiderar a sua formação humanística e cultural.

Considerando a grade curricular dos cursos de idiomas da EAN, optamos, inicialmente, por trabalhar com quatro cursos: Português nível intermédio, português nível intermédio avançado, curso de tradução português-espanhol para os alunos do nível avançado, e uma disciplina optativa do curso de Relações 
Internacionais intitulada Negociacion Intercultural. Tendo em vista a abordagem adotada no projeto, consideramos complicada a distribuição dos cursos por níveis, pois constrói a ideia de uma proficiência sequencial e linear, por isso, optamos por focar nossa atenção na disciplina eletiva Negociacion Intercultural. Essa disciplina tem como objetivo interpretar as estratégias de negociação intercultural a partir do reconhecimento conceitual, teórico e prático da negociação, sendo composta por um grupo heterogêneo de alunos. Importante mencionar que a disciplina não segue um modelo linear e sequencial de proficiência linguística preocupado com o desenvolvimento modular de competências linguísticas, fato que justificou a sua relevância para esta pesquisa. Ademais, o projeto problematizou também o conceito de proficiência à luz da desenvoltura dos alunos em relação ao seu domínio das práticas linguísticas (Pennycook, 2010), o que ficou mais evidente na disciplina eletiva do que nas disciplinas diretamente focadas no ensino da Língua Portuguesa.

Vale ressaltar que os estudantes que participaram desta pesquisa são todos colombianos, em sua grande maioria nascidos em Bogotá. Ao ingressarem na faculdade, os estudantes da EAN devem escolher o idioma com o qual trabalharão no decorrer do curso, dentre os quais português, inglês, italiano, francês e alemão. A escolha da língua portuguesa, para muitos estudantes, ocorre devido à uma identificação com o idioma e com a cultura brasileira, sendo que alguns deles pretendem viajar ao Brasil para realizar seus estágios profissionais e trabalhar com português em um futuro próximo no âmbito do modelo dos negócios. Nesse projeto, para além de uma certa identificação, em uma espécie de espelhamento intercultural, buscamos apreender a maneira como os colombianos reagem discursivamente aos estereótipos e apreciações dos brasileiros sobre eles. Para tanto, a título de ilustração, comentamos a seguir a atividade em que os alunos da disciplina Negociacion Intercultural assistiram ao vídeo $O$ Mundo Segundo os

Brasileiros (https://www.youtube.com/watch?v=y87Ey2mJk-0), em português.

Após assistirem esse vídeo, o docente conduziu um debate misturando português e espanhol (Garcia; Wei, 2014) - sobre o tema e os alunos redigiram, em espanhol, suas apreciações sobre a perspectiva brasileira acerca de Bogotá e da cultura colombiana. Segundo os 
alunos, os brasileiros tendem a hipervalorizar certos aspectos materiais - sistema de ônibus, museus, restaurantes - em detrimento da consideração da realidade social e econômica do país. Essa forma de discursivização fica evidente no vídeo, que tem um apelo turístico forte. Contudo, alguns estudantes teceram comentários sobre uma imagem estereotipada de Bogotá e da Colômbia, já que "não mostra a realidade" . Segundo um outro estudante, "para um residente nativo de Bogotá, não se escuta dizer que Bogotá é uma cidade divertida"4. Dentre as semelhanças identificadas entre brasileiros e colombianos está a ideia de que "seu povo é alegre e caloroso". Importa registrar a maneira como essa atividade mesclou as línguas, as modalidades (escrita, leitura, expressão e compreensão oral) e os gêneros (vídeo de divulgação turística, debate e resenha apreciativa sobre o assunto) na construção de um projeto discursivo compartilhado (Pennycook, 2010; Garcia; Wei, 2014) que teve como resultado uma avaliação intercultural dos alunos sobre as diferentes valorações: de brasileiros sobre Bogotá e de colombianos sobre as apreciações dos brasileiros.

Outro exemplo a mencionar de translinguagem envolvendo línguas, gêneros e modalidades (escrita e oral) na construção de práticas bilíngues foi a atividade realizada por docentes da mesma disciplina, Negociacion Intercultural, em que os estudantes assistiram ao filme Diários de Motocicleta, em português; na sequência, os alunos debateram o tema com o professor - em ambas as línguas - e redigiram um texto em espanhol a partir de questões feitas em português. Trata-se de um filme dirigido por Walter Salles (2004), de caráter autobiográfico, inspirado no diário de viagem de Ernesto Guevara. Importante apontar para alguns aspectos discursivos e interculturais relevantes: tratou-se de motivar discussões políticas e humanísticas, no contexto de uma formação acadêmica "técnica", em que foram abordados temas como: a transformação de Ernesto em

3 "no muestra la realidade". Por questões de sigilo, não mencionaremos informações sobre os estudantes que participaram dos trabalhos. De modo geral, são alunos de classe média de Bogotá, entre as idades de 20 e 30 anos e que cursam o ensino superior na área de Relações Internacionais.

4 "para um residente nativo de Bogotá, no se escucha decir que Bogotá es una ciudad divertida."

5 "su gente es alegre y cálida." 
revolucionário, a relação entre "Muro dos Incas e dos Incapazes", a colonização da América e a subjugação dos povos indígenas. Importante ressaltar a maneira como a mistura (Pennycook, 2010; Garcia; Wei, 2014) de línguas, modalidades e gêneros (filme, relato, debate) convergiram para a construção de um pensamento crítico (Freire, 1996) a respeito da histórica colonial e política da América. Implicitamente, faz-se uma crítica ao sistema capitalista fortemente presente na Colômbia contemporânea. Com isso, os estudantes envolvidos nesta pesquisa puderam, também, expressar seus medos e incertezas vividas em Bogotá.

Essas duas situações analisadas ajudam a ilustrar a maneira como as práticas linguísticas não precisam ser objetivadas para serem ensinadas. Ou seja, em se tratando de processos de negociação de sentidos interculturais, evidencia-se que a proposta comunicativa produz efeitos sobre a maneira como as línguas - portuguesa e espanhola - emergem. Optamos nesse artigo por apresentar experiências didáticas de uma disciplina cujo enfoque principal não é o ensino da língua, mas a Negociação Intercultural, que envolve a apresentação de temas econômicos, políticos sociais e culturais das geopolíticas cujas línguas são usadas. Ao focar os processos envolvidos na negociação intercultural, a disciplina possibilita inscrever os alunos em práticas comunicativas e gêneros discursivos contextualizados, em diálogo com sua formação profissional e acadêmica. Ou seja, ao não se ocupar prioritariamente com a objetivação e sistematização da língua portuguesa para seu ensino (PLE) e não assumir uma formatação estritamente acadêmica (com foco nos gêneros acadêmicos), a disciplina possibilitou a emergência de práticas comunicativas em que as línguas portuguesa e espanhola estiveram a serviço da construção e interpretação de sentidos.

Dessa forma, optamos por enfocar essa disciplina eletiva, em detrimento das demais específicas, com fins de evidenciar a maneira como uma cultura bilíngue pode ser fomentada mediante outras disciplinas cujos enfoques permitem mobilizar uma série de gêneros discursivos. Por vezes, o currículo engessado não possibilita aos docentes fomentar práticas comunicativas e interculturais que acontecem no dia-a-dia da vida docente. Nesse sentido, concordamos com Geraldi (2003, p. XXVIII) ao afirmar que "a práxis exige construção, permanente, sem cristalizações de caminhos. Na práxis, 
alteram-se sujeitos envolvidos e percepções sobre o objeto". Trata-se, com isso, de considerar as práticas de ensino-aprendizagem contextualizadas em uma realidade fluida e dinâmica, em que a perspectiva dos alunos também é relevante para definir o que conta como língua. O ponto de vista dos alunos importa, pois muitas vezes não controlamos a aprendizagem, a despeito do planejamento detalhado dos programas de ensino.

Reconhecemos, então, que a finalidade discursiva não é o ensino e aprendizagem da língua portuguesa, mas os processos (políticos, econômicos, culturais) de construção, negociação e recepção dos sentidos.

\section{Palavras finas}

Este artigo teve como proposta compartilhar, de forma fundamentada teórico-metodologicamente, alguns resultados do projeto "Enseñanza del portugués a partir de géneros discursivos propios del entorno empresarial", conduzido na Escuela de Administración de Negocios, uma faculdade colombiana de enfoque empresarial. Tratou-se de explorar uma perspectiva de língua como prática social que prioriza os processos de produção, negociação e recepção dos sentidos em detrimento de um olhar objetificante, modular e autônomo de língua cuja aprendizagem seguiria um modelo linear e sequencial com o objetivo de aquisição de uma suposta proficiência linguística. Optamos, neste artigo, por enfocar duas experiências de ensino-aprendizagem ocorridas na disciplina eletiva de Negociação Intercultural, mostrando a maneira como a hibridização de línguas, gêneros e modalidades não deve ser vista como um "problema", mas como constitutivos dos processos comunicativos e interculturais. Ademais, nesse projeto buscou-se aproximar a concepção de língua como prática social - conforme os gêneros discursivos - de uma abordagem bilíngue centrada na ideia de translinguagem.

Finalizando, propomos que o ensino de português como língua estrangeira deve estar menos ocupado com a construção de um novo objeto teórico e didático - o PLE - e mais com a construção de espaços de interlocução, comunicação e negociação intercultural, em 
que as línguas emergem como produto da comunicação e não o inverso. Com isso, a cultura bilíngue pode ser fomentada a partir da valorização de práticas comunicativas cujos projetos discursivos favoreçam diálogos e compartilhamentos plurais.

\section{Referências}

ACOSTA-PEREIRA, Rodrigo; RODRIGUES, Rosângela H. Perspectivas atuais sobre gêneros do discurso no campo da Linguística. Letra Magna, v. 5, p. 1-18, 2009.

BAKHTIN, Mikhail. Os gêneros do discurso (1952-53). In: Estética da criação verbal. São Paulo: Martins Fontes, 1992. p. 261306.

. O problema do texto (1959-61). In: BAKHTIN, M. Estética da criação verbal. São Paulo: Martins Fontes, 1992. p. 307-336.

. Questões de literatura e de estética. São Paulo: Unesp/Hucitec, 1988.

BLOMMAERT, Jan. The sociolinguistics of globalization. Cambridge: Cambridge University Press, 2010.

CANAGARAJAH, Suresh (Org.). Reclaiming the local in language policy and practice. London, New York: Taylor \& Francis Group, 2004.

CAVALCANTI, Marilda.; BORTONI-RICARDO, Stella M. (Orgs.). Transculturalidade, linguagem e educação. Campinas, SP: Mercado das Letras, 2007.

CORRÊA. Leda. O status da variedade brasileira do português no Mercosul: delineamento de uma pesquisa em curso. Revista SIPLE, ano 2, n. 2, [s.p.], 2011. Disponível em: 〈http://www.siple.org.br $>$. Acesso em: 01 fev. 2016. 
DINIZ, Leandro R. A. Entre discursos mercadológicos e nacionalistas: apontamentos para o ensino-aprendizagem de português para falantes de outras línguas. Entremeios: Revista de Estudos do Discurso, v.10, p. 5-8, jan.-jun. 2015 Disponível em: 〈http://www.entremeios.inf.br >. Acesso em: 20 jan. 2016.

FREIRE, Paulo. Pedagogia do oprimido. 17. ed. Rio de Janeiro: Paz e Terra, 1987.

- Pedagogia da autonomia: saberes necessários à prática educativa. São Paulo: Paz e Terra, 1996.

GARCÍA, Ofelia, WEI, Li. Translanguaging: language, bilingualism and education. New York: Palgrave Macmillan, 2014.

GARCÍA, Ofelia. Bilingual education in the 21st century: a global perspective. Malden, MA and Oxford: Basil/Blackwell, 2009.

GERALDI, João Wanderley. Portos de Passagem. São Paulo: Martins Fontes, 2003.

KLEIMAN, Angela B. (Org.). Os significados do letramento: uma nova perspectiva sobre a prática social da escrita. Campinas: Mercado de Letras, 1995.

(Org.) Leitura e interdisciplinaridade: tecendo redes nos projetos da escola. Campinas: Mercado de Letras, 1999.

NASCIMENTO, Elvira; ROJO, Roxane R. (Orgs.). Gêneros de texto/discurso e os desafios da contemporaneidade. 1. ed. Campinas, SP: Pontes Editores, 2014.

MASSELO, Laura. Construir o PLE nos países: abertura de caminhos para o ensino de português no Sul da América Latina. Revista SIPLE, ano 1, n. 1, [s.p.], 2010. Disponível em: 〈http://www.siple.org.br〉. Acesso em: 01 fev. 2016. 
MOITA LOPES, Luiz Paulo. Por uma linguística aplicada indisciplinar. São Paulo: Parábola, 2006.

NETO, Francisco T.Castro et al As línguas do ABC: o antes e o depois do Mercosul na história do ensino de PLE na Argentina e no Chile e de ELE no Brasil. Revista SIPLE, ano 4, n. 1, [s.p.], 2013. Disponível em: <http://www.siple.org.br>. Acesso em: 01 fev. 2016.

PENNYCOOK, Alastair. Language as a local practice. Londres; Nova York: Routledge, 2010.

. Principled polycentrism and resourceful speakers. Journal of Asia Tefl, v. 11, n. 4, p.1-19, 2014.

ROJAS, Juan Pedro. Portunhol: fossilização consentida da interlíngua de hispanofalantes aprendizes de PLE? Revista SIPLE, ano 1, n. 1, [s.p.], 2010. Disponível em: 〈http://www.siple.org.br〉. Acesso em: 01 fev. 2016.

SEVERO, Cristine G. A açucarada língua portuguesa: lusotropicalismo e lusofonia no século XXI. Revista Brasileira de Linguistica Aplicada, v. 15 , n. 01 , p. $85-107,2015$.

SILVA, Diego B. De flor do Lácio à língua global. Jundiaí: Paco Editorial, 2013.

ZOPPI FONTANA, Mónica (Org.). O português do Brasil como língua transnacional. Campinas: Editora RG, 2009.

Recebido em: 16/06/2017 Aceito em: 21/02/2017

Title: Between Portuguese as a foreign language and intercultural communicative practices: a case study in a Colombian university 